\title{
Analysis of pressure losses in the diffuser of a control valve
}

\author{
Petr Turecký ${ }^{1}$, Lukáš Mrózek ${ }^{2 *}$, Ladislav Tajč ${ }^{2}$, and Michal Kolovratník ${ }^{3}$ \\ ${ }^{1}$ ENVIROS, s.r.o., Dykova 53/10, 10100 Praha 10-Vinohrady, Czech Republic \\ ${ }^{2}$ Univerzity of West Bohemia, Department of Power System Engineering, Univerzitní 22 Pilsen 306 14, Czech Republic \\ ${ }^{3}$ Czech Technical University in Prague, Department of Energy Engineering, Technická 4, Prague 6, Czech Republic
}

\begin{abstract}
The pressure loss in the diffuser of a control valve is evaluated by using CFD computations. Pressure ratios and lifts of a cone for the recommended flow characteristics of an experimental turbine are considered. The pressure loss in a valve is compared with the pressure loss in a nozzle, i.e. the embodiment of the valve without a cone. Computations are carried out for the same mass flow. Velocity profiles are evaluated in both versions of computations. Comparison of computed pressure losses, with the loss evaluated by using relations for diffusers with the ideal velocity conditions in the input cross-section, is carried out.
\end{abstract}

\section{Introduction}

Control valves of steam turbines are basically nozzles with a variable cross-section. A confuser as well as a diffuser channel is applied here. The change of the mass flow of the steam is enabled by adjustment of the flow area and pressure ratio across the valve. The flow area depends on the lift of a cone and the pressure ratio is determined by the operating parameters of a turbine. A sudden change of the cross-section arises in the valve under the cone. A wake vortex arises under the cone, which distorts the velocity field in the diffuser. At a certain stage of the operation control, i.e. when the turbine approaches the power, a pressure loss across the valve is required. In this case the operational reliability is most important. Emphasis is placed on the control of pressure pulsations and thus extreme vibrations are controlled too. However, during nominal conditions of the turbine it is required the minimum pressure loss in the entire flow system before the turbine. In general, the pressure loss is related to friction and shape modifications of the valve. The decisive proportion of the pressure loss is caused by a sudden change of the cross-section. An outlet diffuser is used in the valve, therefore it is impossible to specify clearly for what change of the flow area this loss must be considered. Behind the cone of the valve the wake vortex arises with the flow separation. In the diffuser at small lifts of a cone the backflow arises, which may fill up its substantial part. There is a significant deformation of velocity field in the throat as well as in the entire diffuser. Available literature data for computation of the pressure loss in diffusers are based on the existence of the balanced velocity field at the inlet into the diffuser. The aim of this computation study is to evaluate the impact of the wake vortex on the increase of the pressure loss in the diffuser. Geometry of a valve with a cone and without a cone is modelled and the pressure losses are computed for the same mass flow.

\section{Operational parameters of a control valve}

Model version of a control valve is shown in figure 1 .

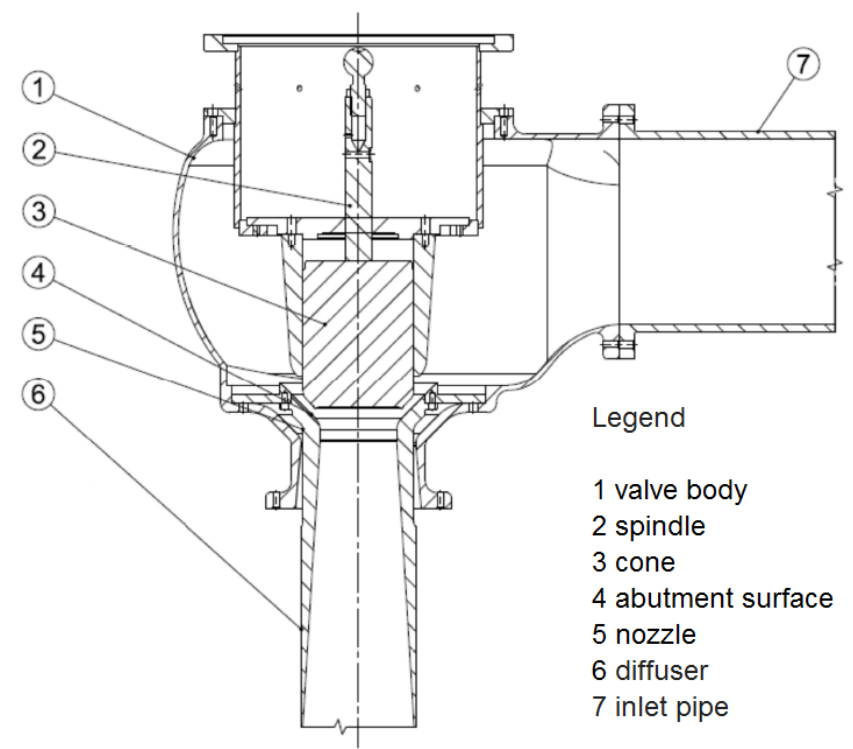

Fig. 1. Scheme of control valve

With the change of the cone lift of a valve $h$ the flow area of the valve changes too. Mass flow through a valve is determined by the flow area, input parameters and pressure ratio across that valve. Figure 2 shows the general flow characteristics of the typical embodiment of a valve in dimensionless parameters [5]. The real mass flow $G$ is related to the critical flow $G_{*}$, which is considered for the area of the throat of the diffuser $D_{h}$. 


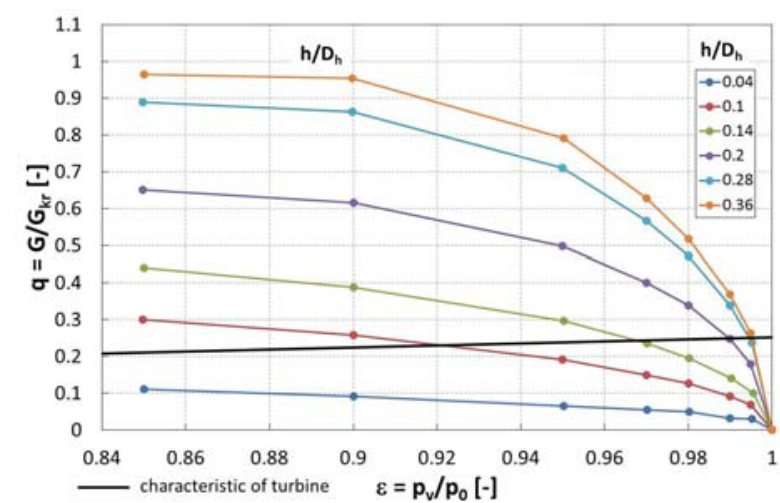

Fig. 2. Flow characteristics of valves

There is also presented expected operational characteristics of the experimental turbine. Relevant pressures and temperatures are shown in table 1. The computation study is carried out for these recommended pressure ratios and cone lifts. In table 2 are shown other characteristic data of the tested valve, respectively of a computational model of the diffuser.

Table 1. Specified parameters for the simulation

\begin{tabular}{|c|c|c|c|}
\hline$h[\mathrm{~mm}]$ & $\left(p_{v}\right)_{v}[\mathrm{~Pa}]$ & $p_{0 c}[\mathrm{~Pa}]$ & $T_{0}[\mathrm{~K}]$ \\
\hline 4 & 40968 & & \\
\cline { 1 - 2 } 6 & 51051 & & \\
\cline { 1 - 2 } 8 & 67717 & & \\
\cline { 1 - 2 } 10 & 79989 & & \\
\hline 14 & 91086 & \multirow{2}{*}{290000} & \\
\hline 20 & 96067 & & \\
\hline 24 & 97114 & & \\
\hline 28 & 97655 & & \\
\hline 36 & 97792 & & \\
\hline
\end{tabular}

Table 2. Initial values

\begin{tabular}{|l|c|r|l|}
\hline Inlet pressure & $p_{0 c}$ & 100 & $\mathrm{kPa}$ \\
\hline Inlet temperature & $T_{0}$ & 294 & $\mathrm{~K}$ \\
\hline Heat capacity ratio & $\kappa$ & 1.4 & - \\
\hline Specific gas constant & $r$ & 287 & $\mathrm{~J} / \mathrm{kgK}$ \\
\hline Length & $l$ & 400 & $\mathrm{~mm}$ \\
\hline Diameter of diffuser throat & $D_{h}$ & 100 & $\mathrm{~mm}$ \\
\hline Angle of diffuser opening & $\gamma$ & 7 & $\circ$ \\
\hline Cross section of diffuser throat & $S_{h}$ & 7854 & $\mathrm{~mm}$ \\
\hline Density & $\rho_{0}$ & 1.185 & $\mathrm{~kg} / \mathrm{m}^{3}$ \\
\hline Area ratio & $n$ & 2.218 & - \\
\hline
\end{tabular}

\section{Computational models}

A computational model of a valve is presented in figure 3. It is a simplified version of the normal performance of a valve. Instead of the real 3D flow in the valve chamber and in the diffuser, only the rotationally symmetrical arrangement is considered, i.e. only the variant with the 2D flow.

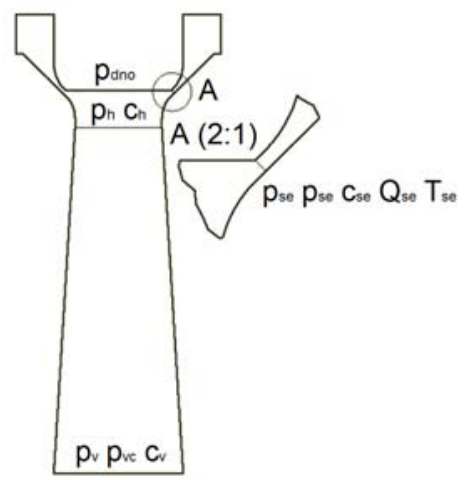

Fig. 3. A computational model of a valve

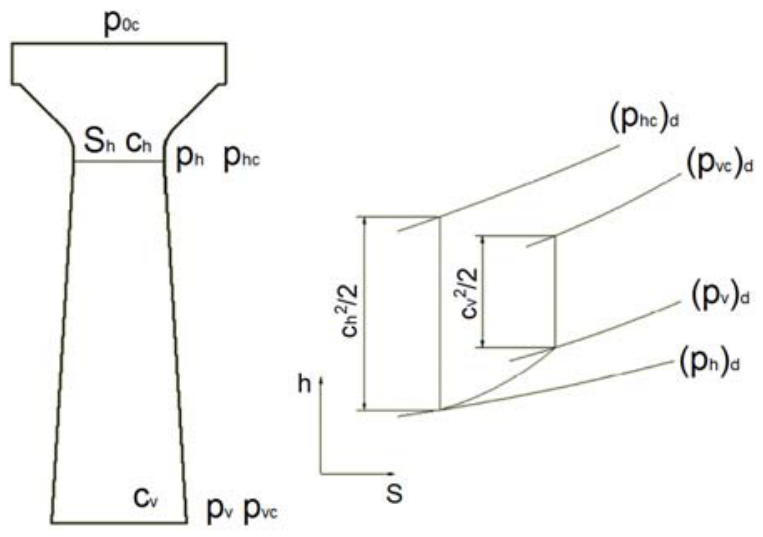

Fig. 4. A computational model of a nozzle

Extension of the flow channel arises already from the area of the saddle under the cone. In the variant of a nozzle as shown in figure 4, only the diffuser itself is considered with the steady area of the neck $S_{h}$. In order to achieve the same mass flow in a nozzle as in a valve, an appropriate back pressure $p_{v}$ behind the diffuser must be present. As a result of the wake vortex formation and a sudden change of the cross-section, the pressure loss in the variant of a valve $\Delta p_{z}=p_{0 c}-p_{v c}$ is higher than in a nozzle. CFD simulation of the $2 \mathrm{D}$ model of a control valve and a nozzle is carried out by using the ANSYS Fluent software. For individual sections of the flow channel the different density of the mesh was chosen. As a result, there are 614000 cells in a valve model and 436000 cells in a nozzle.

\section{Results}

Nine CFD simulations for the stated cone lifts and recommended pressure ratios were carried out in the variant of a valve. Nine computations of flowing in a nozzle with the same mass flow as in the variant with the 
valve were added to it.

The demonstration of the velocity distribution in the variant of a valve and a nozzle is shown in figure 5 . These are variants corresponding to the cone lift $6 \mathrm{~mm}$ $\left(h / D_{h}=0.06\right)$.

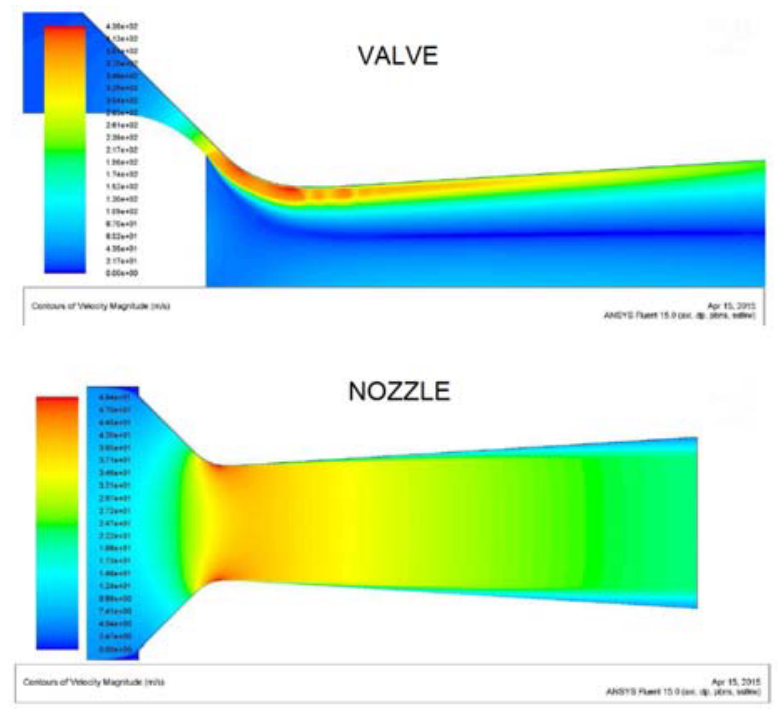

Fig. 5. The velocity field in a variant of a valve and a nozzle at the same mass flow

From the detailed distribution of the velocity vectors in figure 6 the backflow and significant changes of the velocity in a narrow strip by the diffuser wall is clearly seen. The backflow does not occur in a nozzle. Computation also confirms the pressure fluctuation near by the diffuser wall at relative cone lift $h / D_{h}<0.08$.

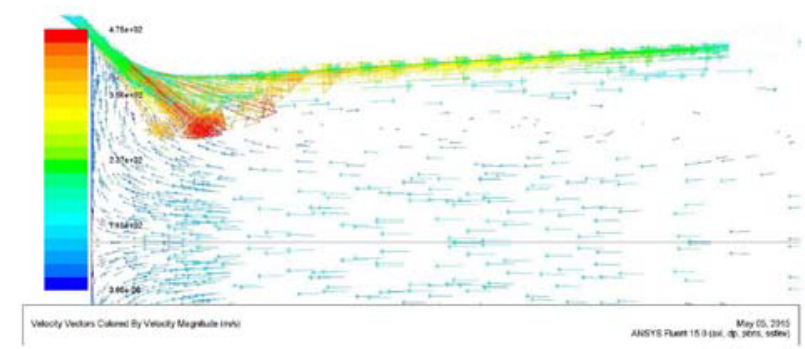

Fig. 6. The vector velocity distribution

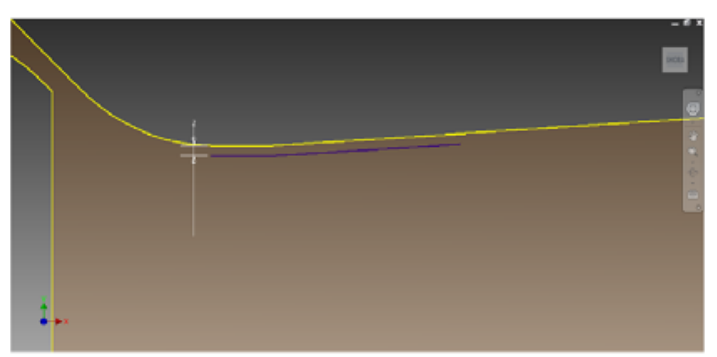

Fig. 7. Section of velocity changes near the wall

Analysis of pressure pulsations and velocity changes for the section of the diffuser behind its throat in the zone $2 \mathrm{~mm}$ from the wall is carried out. This is shown in figure 7. Fluctuation of the static pressure and velocity is presented in the graphs in figures 8 and 9. Occurrence of pressure pulsations is connected to local occurrence of supersonic velocities.

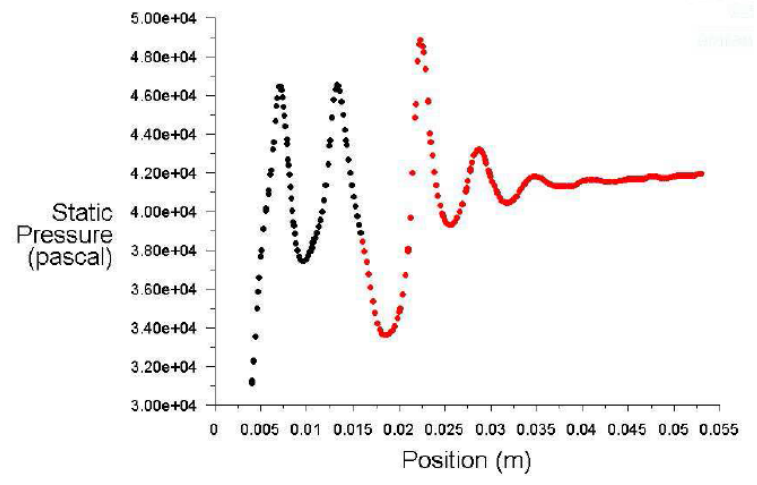

Fig. 8. Fluctuation of the static pressure

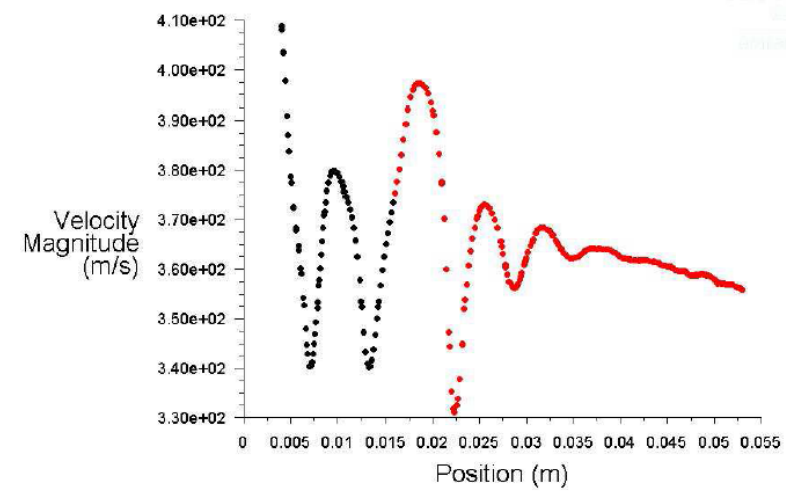

Fig. 9. Fluctuation of velocities by the wall

After the transition to higher cone lifts when Mach number in the diffuser throat is already $M a<1$, the pressure pulsation failed to verify by using computations. However, as the result of flushing the vortexes behind the cone the pressure changes undoubtedly occur.

Due to the wake vortex behind a cone the velocity field in the diffuser throat is significantly distorted. Maximum velocity occurs near the diffuser wall while in its middle section the velocity may have even a negative value. Velocity ratios for a valve with proportional cone lift $h / D_{h}=0.04$ and for a nozzle with the same mass flow are shown in figure 10. Considerably uneven velocity field also occurs at the outlet from the diffuser. Even at the cone lift $h / D_{h}=0.2$ in the diffuser throat a backflow occurs. Velocity ratios of this variant of computation are presented in figure 11. If the nozzle embodiment (a valve without a cone) is considered, then the velocity field is very balanced in individual crosssections.

Values of computed averaged quantities in the saddle, in the throat and at the outlet from the valve are presented in table 3 . The data for a nozzle are shown in table 4. 

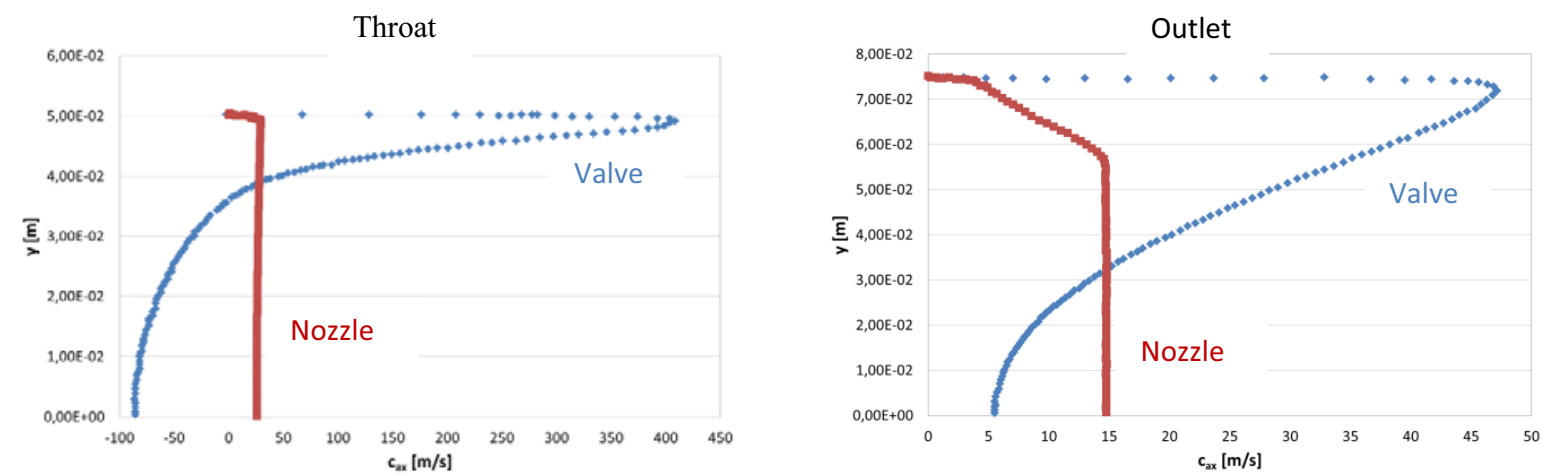

Fig. 10. Velocity profile in the cross section of the throat and outlet from the diffuser at the lift $h / D_{h}=0.04$
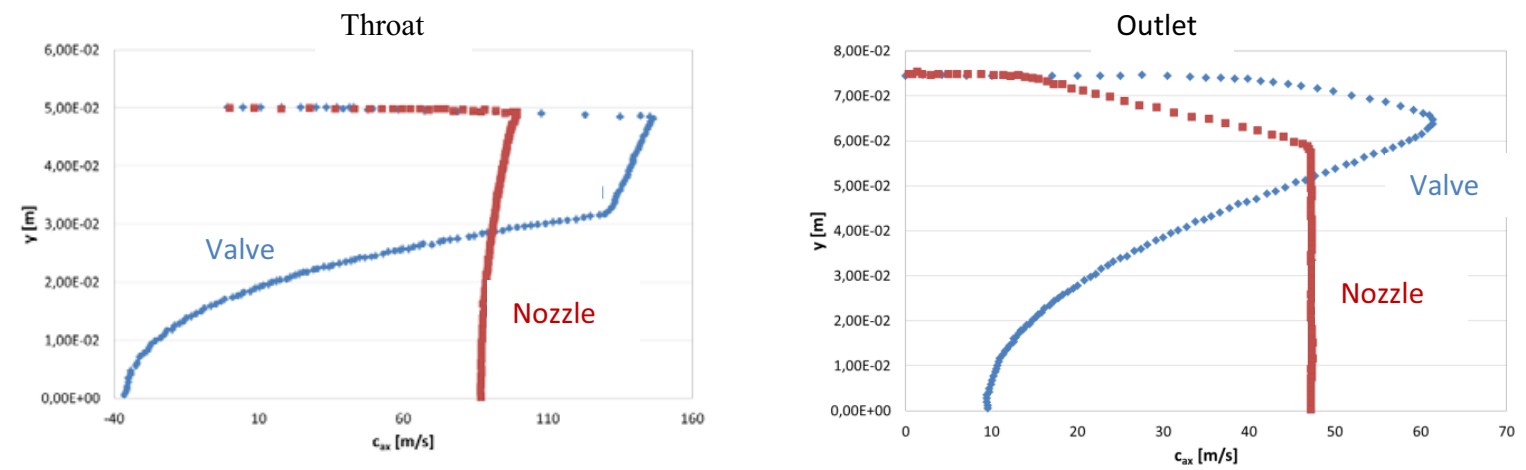

Fig. 11. Velocity profile in the cross section of the throat and from the diffuser outlet at the lift $h / D_{h}=0.2$

Table 3. Table of averaged quantities in the saddle, in the throat and at the outlet from the valve

\begin{tabular}{|c|c|c|c|c|c|c|c|c|c|c|c|c|c|}
\hline$h$ & $S_{s e}$ & $G$ & $c_{s e}$ & $c_{v}$ & $\left(p_{s e}\right)_{v}$ & $\left(p_{d n o}\right)_{v}$ & $\left(M a_{s e}\right)_{v}$ & $\rho_{s e}$ & $T_{s e}$ & $\left(p_{h}\right)_{v}$ & $\left(p_{s e c}\right)_{v}$ & $\left(p_{v c}\right)_{v}$ & $\left(p_{v}\right)_{v}$ \\
\hline$[\mathrm{mm}]$ & {$\left[\mathrm{mm}^{2}\right]$} & {$[\mathrm{kg} / \mathrm{s}]$} & {$\left[\mathrm{m} / \mathrm{s}^{2}\right]$} & {$\left[\mathrm{m} / \mathrm{s}^{2}\right]$} & {$[\mathrm{Pa}]$} & {$[\mathrm{Pa}]$} & {$[-]$} & {$\left[\mathrm{kg} / \mathrm{m}^{3}\right]$} & {$[\mathrm{K}]$} & {$[\mathrm{Pa}]$} & {$[\mathrm{Pa}]$} & {$[\mathrm{Pa}]$} & {$[\mathrm{Pa}]$} \\
\hline 4 & 1094 & 0.252 & 313.45 & 35.53 & 52201 & 26963 & 1.000 & 0.742 & 245 & 28000 & 98816 & 41303 & 40968 \\
\hline 6 & 1654 & 0.383 & 305.98 & 44.20 & 54104 & 37642 & 0.971 & 0.762 & 247 & 35417 & 99113 & 52119 & 51051 \\
\hline 8 & 2223 & 0.508 & 276.3 & 44.92 & 61094 & 56487 & 0.862 & 0.831 & 256 & 51208 & 99321 & 68614 & 67717 \\
\hline 10 & 2801 & 0.589 & 224.11 & 44.86 & 72870 & 70341 & 0.682 & 0.944 & 269 & 66284 & 99549 & 81049 & 79989 \\
\hline 14 & 3984 & 0.677 & 161.83 & 45.66 & 85105 & 83539 & 0.482 & 1.055 & 281 & 80841 & 99784 & 92338 & 91086 \\
\hline 20 & 5824 & 0.828 & 129.76 & 47.70 & 90245 & 88846 & 0.383 & 1.101 & 286 & 87582 & 99880 & 97468 & 96067 \\
\hline 24 & 7096 & 0.909 & 114.97 & 50.00 & 92288 & 90902 & 0.338 & 1.119 & 287 & 89591 & 99912 & 98677 & 97114 \\
\hline 28 & 8403 & 0.929 & 97.67 & 50.37 & 94390 & 93228 & 0.287 & 1.137 & 289 & 90795 & 99938 & 99233 & 97655 \\
\hline 36 & 11123 & 0.996 & 77.94 & 53.14 & 96401 & 95484 & 0.228 & 1.154 & 291 & 90463 & 99962 & 99523 & 97792 \\
\hline
\end{tabular}

Table 4. Quantities in the throat and at the outlet from nozzle

\begin{tabular}{|c|c|c|c|c|}
\hline $\mathrm{h}[\mathrm{mm}]$ & $\left(p_{h c}\right)_{d}[\mathrm{~Pa}]$ & $\left(p_{v c}\right)_{d}[\mathrm{~Pa}]$ & $\left(p_{v}\right)_{d}[\mathrm{~Pa}]$ & $\left(p_{h}\right)_{d}[\mathrm{~Pa}]$ \\
\hline 4 & 99995 & 99981 & 99871 & 99551 \\
\hline 6 & 99989 & 99960 & 99711 & 98961 \\
\hline 8 & 99981 & 99933 & 99498 & 98157 \\
\hline 10 & 99975 & 99912 & 99329 & 97507 \\
\hline 14 & 99968 & 99885 & 99118 & 96684 \\
\hline 20 & 99952 & 99830 & 98679 & 94932 \\
\hline 24 & 99943 & 99796 & 98411 & 93838 \\
\hline 28 & 99940 & 99787 & 98338 & 93537 \\
\hline 36 & 99931 & 99755 & 98085 & 92481 \\
\hline
\end{tabular}

From the computations it is possible to specify, by using different methods, the value of the loss coefficient for the computation of occurred pressure loss $\left(\Delta p_{z}\right)_{v}=p_{s e c}-p_{v c}$. We can consider the dynamic pressure in the valve saddle, in the diffuser throat, at the diffuser outlet or the pressure on the bottom of the cone.

$$
\begin{aligned}
& \left(\Delta p_{z}\right)_{v}=\zeta_{s e}\left(\mathrm{p}_{s e c}-\mathrm{p}_{s e}\right)_{v} \\
& \left(\Delta \mathrm{p}_{z}\right)_{v}=\zeta_{d n o}\left(\mathrm{p}_{s e c}-\mathrm{p}_{d n o}\right)_{v} \\
& \left(\Delta \mathrm{p}_{z}\right)_{v}=\zeta_{h}\left(\mathrm{p}_{s e c}-\mathrm{p}_{h}\right)_{v} \\
& \left(\Delta p_{z}\right)_{v}=\zeta_{v}\left(p_{s e c}-p_{v}\right)_{v}
\end{aligned}
$$


Their course depending on the relative lift of a cone is shown in figure 12. The pressure on the bottom of the cone is similar to the pressure in the diffuser throat. The course of loss coefficients corresponds to it.

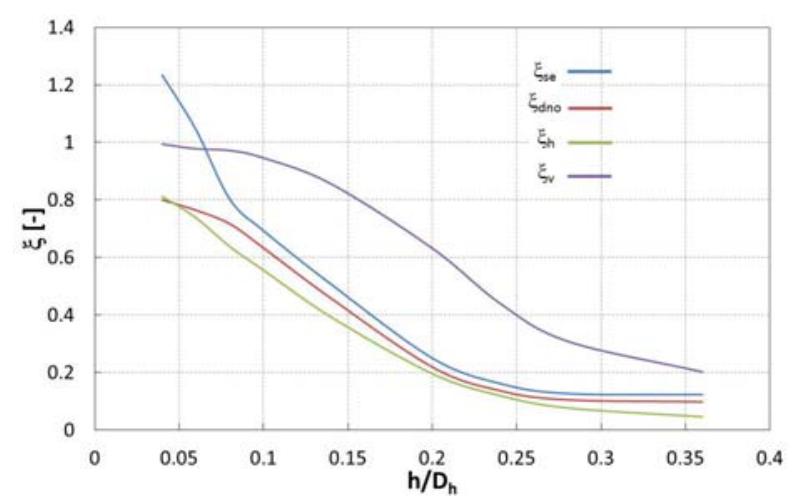

Fig. 12. The course of loss coefficients

With the gradual opening of the valve the pressure loss decreases and therefore the value of all pressure coefficients decreases too. At the maximum lift of a cone the pressure loss reaches up to $20 \%$ of the total pressure differential across the diffuser. At small lifts of a cone the critical pressure ratio is set in the saddle of the valve and the increase of loss coefficient $\zeta_{s e}$ corresponds to it.

In embodiment of a nozzle it is on the contrary. The highest pressure loss arises at the maximum flow of the media through a nozzle. The pressure loss at the nozzle is $\left(\Delta p_{z}\right)_{d}=\left(p_{h c}-p_{v c}\right)_{d}$. From comparison of pressure losses for a valve and for a nozzle we can evaluate the relevant loss coefficient $\zeta_{d}$, where $\left(\Delta p_{z}\right)_{v}=\zeta_{d}\left(\Delta p_{z}\right)_{d}$. It is the flow for considered relative lifts $h / D_{h}$. It is presented in figure 13. The loss coefficient $\zeta_{d}$ appears to change from infinity to zero.

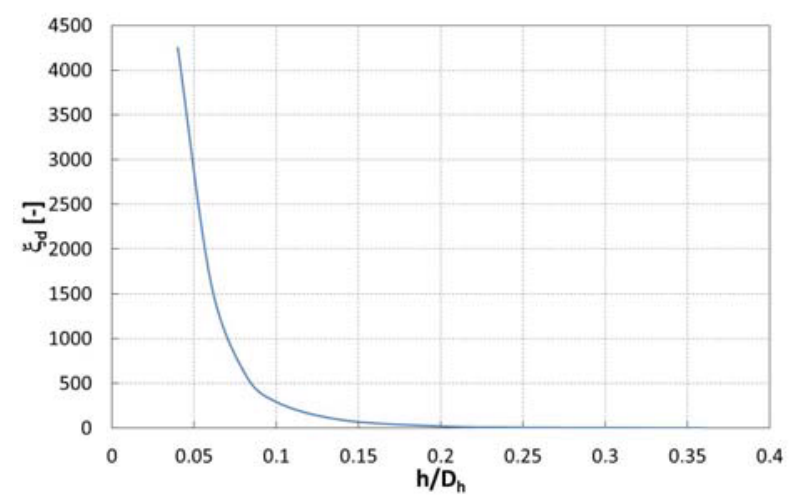

Fig. 13. Dependence of the loss coefficient of a nozzle proportional lift

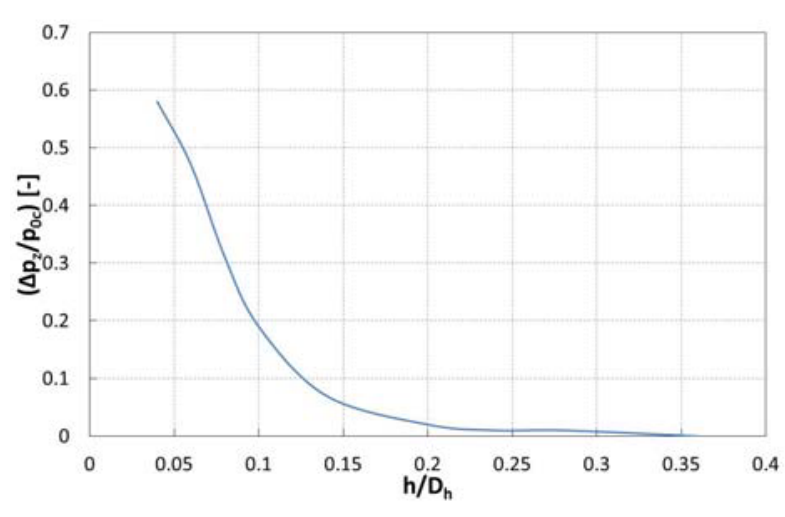

Fig. 14. Dependence of the proportional pressure loss on the proportional lift

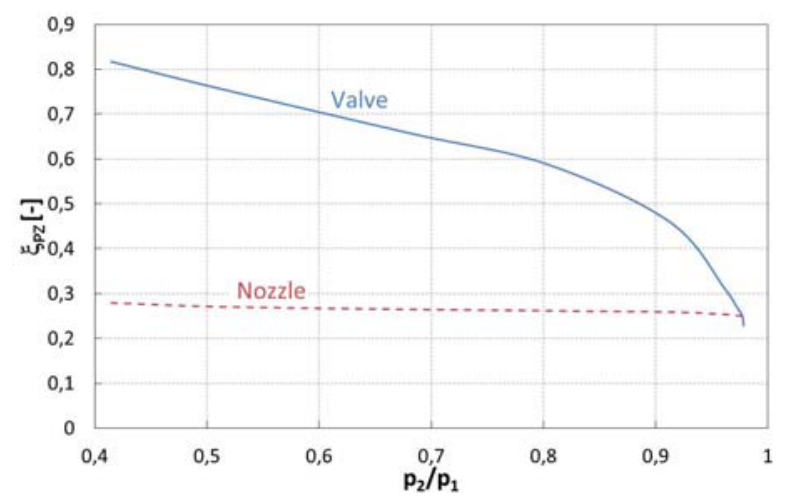

Fig. 15. Dependence of the loss pressure coefficient on the proportional pressure at the outlet

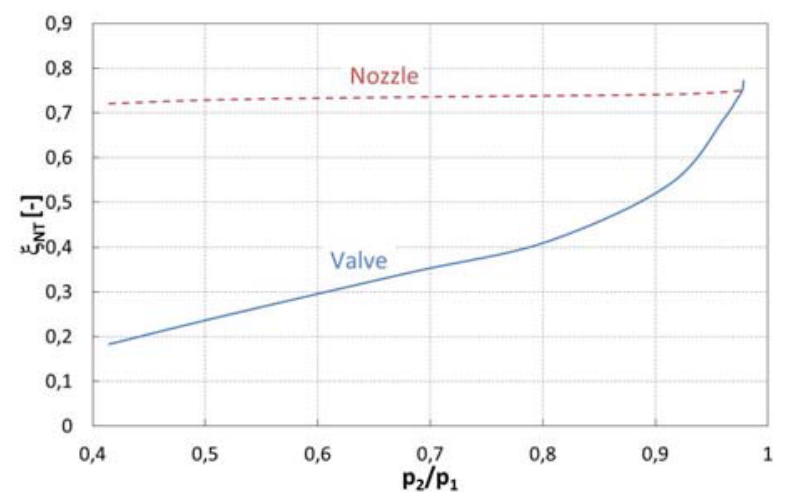

Fig. 16. Dependence of the coefficient of pressure increase on the proportional pressure at the outlet

Expression of the pressure loss in the valve using the pressure loss in the nozzle in the stated form is not for practical purposes suitable. In turbine practice the pressure loss is evaluated as the proportional pressure loss of the input pressure. In this form the pressure loss in the diffuser valve is presented in figure 14. The pressure loss at the lift $h \rightarrow 0$ depends on the return pressure. For condensing turbines this pressure is close to zero, therefore throttling the steam in the valve obstructs the entire pressure gradient. 
The quality of processes in diffusers may also be evaluated by using the coefficients of the pressure loss or coefficient of pressure increase. The pressure loss is presented in the graphs in figures 15 and 16. They show the differences in embodiment of a valve and a nozzle.

- Valve

$$
\begin{array}{r}
\zeta_{P Z_{v}}=\frac{1-\frac{p_{v}}{p_{s e c}}}{1-\frac{p_{h}}{p_{s e c}}} \\
\zeta_{N T_{v}}=\frac{\frac{p_{v}}{p_{s e c}}-\frac{p_{h}}{p_{s e}}}{1-\frac{p_{h}}{p_{s e c}}}
\end{array}
$$

- Nozzle

$$
\begin{gathered}
\zeta_{P Z_{d}}=\frac{1-\frac{p_{v}}{p_{h c}}}{1-\frac{p_{h}}{p_{h c}}} \\
\zeta_{N T_{d}}=\frac{\frac{p_{v}}{p_{h c}}-\frac{p_{h}}{p_{h c}}}{1-\frac{p_{h}}{p_{h c}}}
\end{gathered}
$$

The pressure loss at the valve decreases gradually, whereas the nozzle is constant. The coefficient of the pressure increase shows a similar course. When a valve is fully open the data for a valve and a nozzle are consistent.

In literature $[1,2]$ it is possible to find experimentally evaluated materials for computation of pressure losses in diffusers with ideal velocity ratios at the inlet into the diffuser. Thus for the variant of a nozzle it is possible to compare computed pressure losses with the prediction of the pressure loss according to the literature sources. The loss coefficient according to [2] is considered,

$$
\zeta_{P}=\left[\frac{\lambda}{8 \sin (\gamma / 2)} \frac{n+1}{n-1}+3,2(\operatorname{tg}(\gamma / 2))^{1,25}\right]\left(1-\frac{1}{n}\right)^{2}
$$

where $\gamma$ is the angle of the diffuser opening, $n$ is ratio of the outlet area to the area of the throat and $\lambda$ is the coefficient of friction.

The pressure loss is evaluated as the proportion of inlet dynamic pressure.

$$
\Delta p_{z}=\zeta_{P} \frac{1}{2} \rho c^{2}
$$

Good conformity with the prediction of the pressure loss is confirmed. Comparison of prediction of the pressure loss with the computed loss is presented in figue 17 .

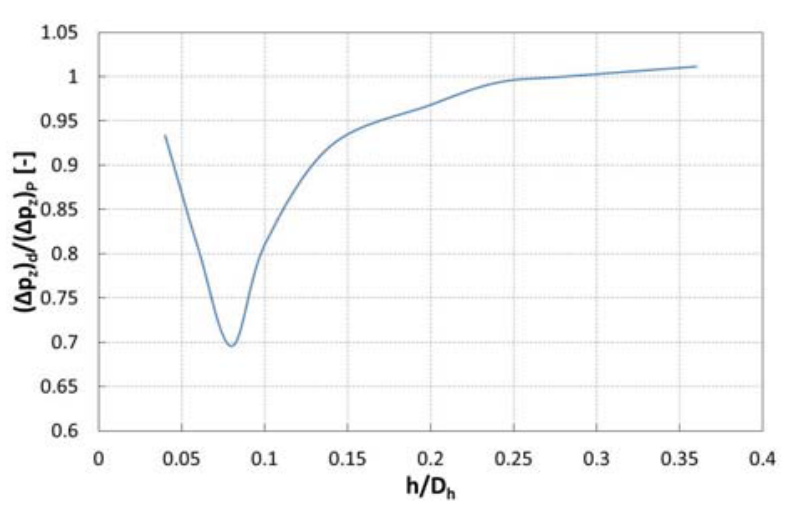

Fig. 17. Comparison of the pressure loss according to literature and from the CFD simulation
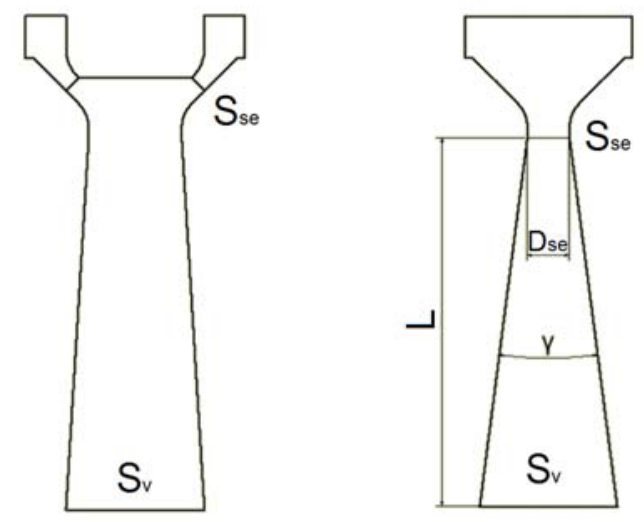

Fig. 18. Adjustment of diffuser geometry

In order to estimate the pressure loss in the diffuser of the valve, besides the loss caused by friction and by extension of the channel, the pressure loss due to the wake vortex must be evaluated too. To achieve this, the geometry of the valve must be adjusted and must be close to embodiment of a nozzle, which means the diffuser with the ideal inlet velocity field. Adjustment of valve geometry is shown in figure 18. The area of the throat changes. the nozzle adapts to this adjustment so that it could correspond to the area of the saddle under the cone of the valve and the angle of the diffuser expansion $\gamma$.

The entire pressure loss has three parts

$$
\Delta p_{z}=\Delta p_{T}+\Delta p_{R}+\Delta p_{U}
$$

The pressure loss caused by friction

$$
\begin{gathered}
\Delta p_{T}=\zeta_{T} \frac{1}{2} \rho c_{s e}^{2}=\zeta_{T}\left(p_{s e c}-p_{s e}\right) \\
\zeta_{T}=\varphi_{T}\left(1-\frac{1}{n}\right)^{2}=\left(\frac{\lambda}{8 \sin (\gamma / 2)} \frac{n+1}{n-1}\right)\left(1-\frac{1}{n}\right)^{2}
\end{gathered}
$$

The pressure loss and loss coefficients by channel expansion $\Delta p_{R}$ and $\zeta_{R}$ is evaluated similarly.

$$
\zeta_{R}=\varphi_{R}\left(1-\frac{1}{n}\right)^{2}=3,2(\operatorname{tg}(\gamma / 2))^{1,25}\left(1-\frac{1}{n}\right)^{2}
$$


The pressure loss caused by wake vortex $\Delta p_{U}$ can be reached when from computed pressure loss in the valve is the loss $\Delta p_{T}+\Delta p_{R}$ deducted.

$$
\begin{gathered}
\Delta p_{U}=\left(\Delta p_{Z}\right)_{V}-\left(\Delta p_{T}+\Delta p_{R}\right)=\varphi_{U}\left(1-\frac{1}{n}\right)^{2} \frac{1}{2} \rho c_{s e}^{2} \\
\zeta_{U}=\varphi_{U}\left(1-\frac{1}{n}\right)^{2}
\end{gathered}
$$

In figure 19 the friction loss coefficient $\zeta_{\mathrm{T}}$ is presented. With a gradual increase of the flow area through the valve, and with the increase of the mass flow, its value increases. However, compared with other factors impacting the final pressure loss it has the least impact.

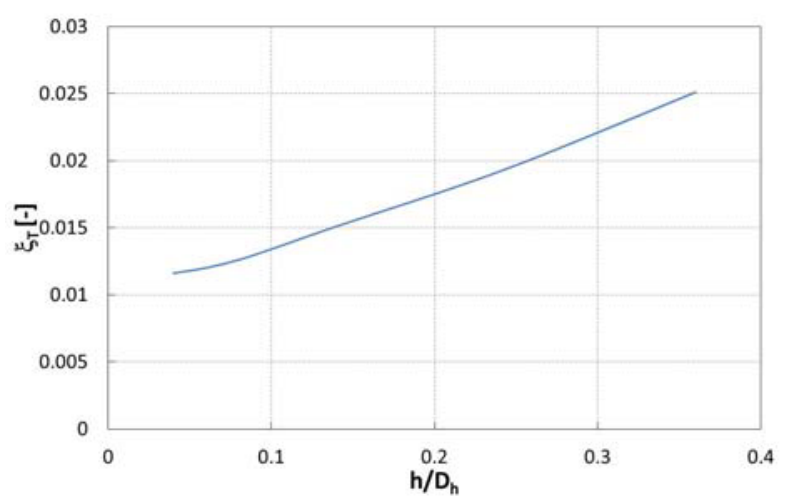

Fig. 19. Dependence of the loss coefficient by friction on the proportional lift

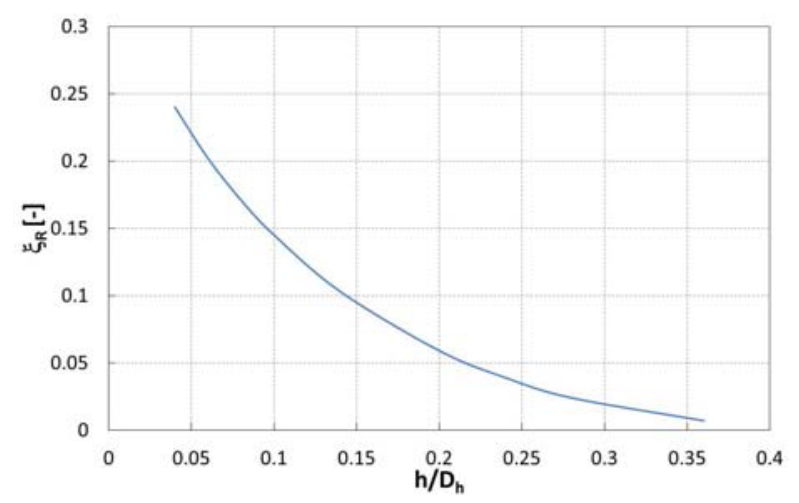

Fig. 20. Dependence of the loss coefficient by expansion on the proportional lift

The loss coefficient of diffuser expansion and the loss coefficient of wake vortex with the cone lift decreases. Their course is presented in figure 20 and figure 21 . The impact of wake vortex on the pressure loss is the most significant. The pressure loss depends on the velocity of steam flowing through a valve. The smaller the dimensions of a valve, the higher are the velocities at a given certain quantity of the steam in the flow section of a valve, which causes the increase of the final pressure loss. The choice of dimension of the flow may impact the pressure loss in the valve under the certain operational conditions of the turbine. Figure 22 shows the range of choice of relative flow rate $q$. If a valve with lower value $q_{\max }$ is used, $\varepsilon_{\max }$ is higher too and thus the pressure loss on the valve is lower.

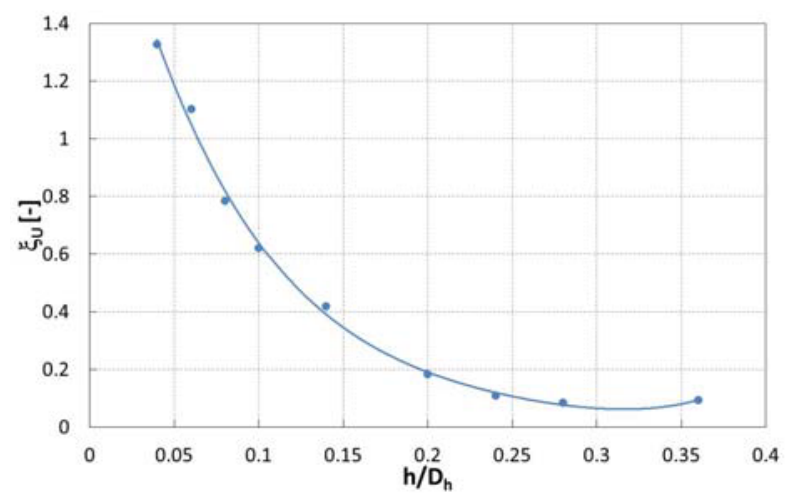

Fig. 21. Dependence of the loss coefficient by wake vortex on the proportional lift

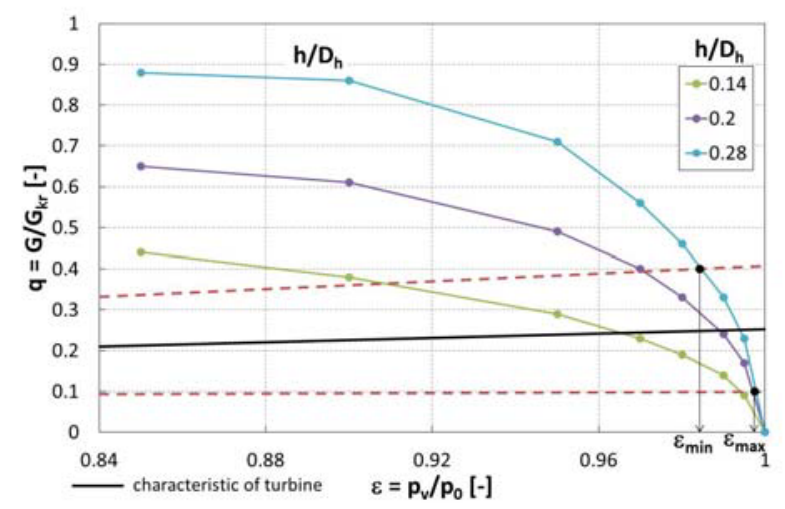

Fig. 22. Range of operating pressure ratios

\section{Conclusion}

- Due to wake vortex under the cone in the diffuser of a control valve the velocity field gets deformed. Backflow occurs in the diffuser. Flow separation from the diffuser wall may occur.

- The highest velocities occur by the diffuser wall close to its throat. This is the place with the occurrence of pressure pulsations at the supersonic steam flow.

- Uneven velocity field also occurs at the outlet from the diffuser.

- The final pressure loss can be evaluated using loss coefficients for a friction, expansion of the diffuser and for impact of the wake vortex. The wake vortex has the highest impact on the pressure loss in the valve.

- Choice of dimensions of the valve can influence the pressure loss in the valve under the certain operational conditions of a turbine.

\section{Nomenclature}

$\begin{array}{ll}c & \text { velocity } \\ h & \text { cone lift } \\ n & \text { area ratio } \\ p & \text { pressure } \\ q & \text { proportional flow }\end{array}$




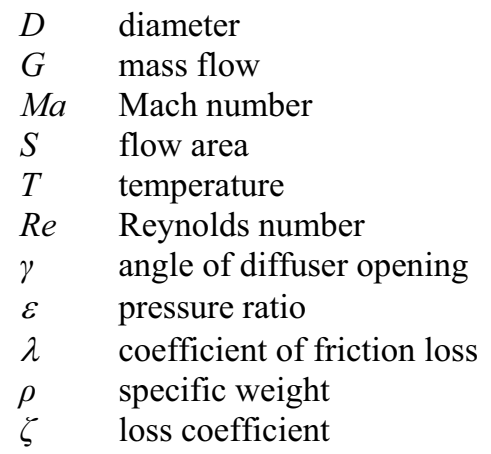

\section{Subscripts}

$\begin{array}{ll}c & \text { total } \\ h & \text { throats } \\ o & \text { inlet } \\ v & \text { outlet } \\ \text { se } & \text { saddle } \\ d n o & \text { bottom of the cone } \\ d & \text { nozzle } \\ a x & \text { axial } \\ z & \text { loss } \\ T & \text { friction } \\ U & \text { wake vortex } \\ R & \text { dimensional } \\ P Z & \text { pressure loss } \\ N T & \text { pressure increase } \\ P & \text { prediction }\end{array}$

\section{References}

1. M. Dejč, Technická dynamika plynů, Praha: SNTL, 659s. (1967)

2. И. Л. Повх, Аэродинамический эксперимент в машиностроении, Ленинград, Машиностроеные Ленинградский отделение, (1974)

3. J. Nožička, Základy termomechaniky, ČVUT Praha, 187s. ISBN 9788001040225, (2008)

4. R. Dvořák, K. Kozel, Matematické metody $v$ aerodynamice, ČVUT Praha, 153s. ISBN 8001008517

5. J. Šesták, Přenos hybnosti, tepla a hmoty, ČVUT Praha, 299s. ISBN 800101715x, (1998)

6. J. Ambrož, Parní turbíny a kondenzace, ČVUT Praha, 281s., (1984) 